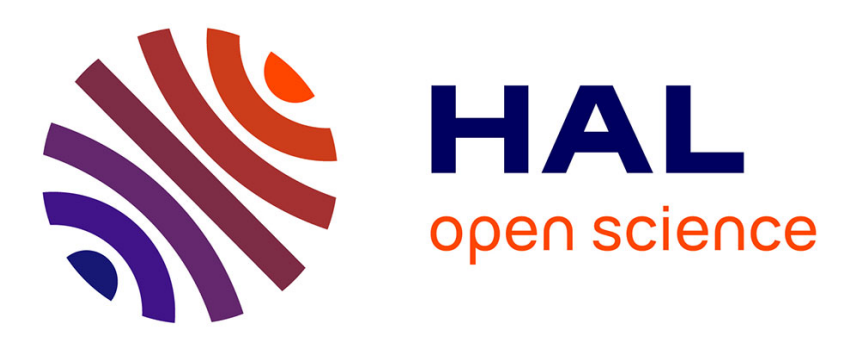

\title{
Geostatistical method for analysing soil displacement from underground urban construction
}

\author{
M. El Gonnouni, Yvon Riou, Pierre-Yves Hicher
}

\section{To cite this version:}

M. El Gonnouni, Yvon Riou, Pierre-Yves Hicher. displacement from underground urban construction.

Geostatistical method for analysing soil 10.1680/geot.2005.55.2.171 . hal-01006918

Geotechnique, 2005, 55 (2), pp.171-182.

\section{HAL Id: hal-01006918}

https://hal.science/hal-01006918

Submitted on 8 Apr 2017

HAL is a multi-disciplinary open access archive for the deposit and dissemination of scientific research documents, whether they are published or not. The documents may come from teaching and research institutions in France or abroad, or from public or private research centers.
L'archive ouverte pluridisciplinaire HAL, est destinée au dépôt et à la diffusion de documents scientifiques de niveau recherche, publiés ou non, émanant des établissements d'enseignement et de recherche français ou étrangers, des laboratoires publics ou privés. 


\title{
Geostatistical method for analysing soil displacement from underground urban construction
}

\author{
M. EL GONNOUNI*, Y. RIOU* and P. Y. HICHER*
}

\begin{abstract}
The aim of this study was to assess the influence of uncertainties related to soil variability in the numerical modelling of settlements caused by underground work. Based on a large number of in situ tests, a geostatistical method, kriging, applied to the stratigraphy of the subsurface was justified and used in order to determine the mean position of the soil layers and their estimation variances. In a first stage, the influence of the uncertainty in the soil stratigraphy on the calculated surface settlements was analysed. In a second stage, a stochastic finite element method was used to introduce the influence of uncertainty in the soil mechanical parameters on the predicted surface settlements.
\end{abstract}

KEYWORDS: numerical modelling; settlement; soil/structure interaction; statistical analysis; tunnels
Cette étude avait pour but d'évaluer l'influence des incertitudes liées à la variabilité du sol dans les modélisations numériques des affaissements causés par les travaux souterrains. En nous basant sur un grand nombre d'essais in situ, nous avons justifié et utilisé une méthode géostatistique, le kriging, appliquée à la stratigraphie des sous-surfaces pour déterminer la position moyenne des couches de sol et leurs variations d'estimation. Dans un premier temps, nous avons analysé l'influence de l'incertitude dans la stratigraphie du sol sur l'affaissement calculé de la surface. Dans un second temps, nous avons utilisé une méthode d'élément fini stochastique pour introduire l'influence de l'incertitude des paramètres mécaniques du sol sur les affaissements de surface prédits.

\section{INTRODUCTION}

The construction of underground engineering projects (such as tunnels, open trenches, subways, and underground passages) in urban sites causes surface settlements, which can affect existing buildings and provoke environmental damage. These kinds of effect can be estimated by deterministic geotechnical analyses, especially numerical methods such as the finite element method. Such modelling may ignore heterogeneity in the geometrical and mechanical characteristics of the soil layers. However, many examples of structural damage observed in underground projects have been shown to be the result of a lack of information on the soil variability.

Many researchers have documented the uncertainty and inherent variability in soil mechanical properties (e.g. Terzaghi, 1955; Haldar \& Tang, 1979; Haldar \& Miller, 1984a, 1984b; Phoon \& Kulhawy, 1999a, 1999b). In an important early paper, Terzaghi (1955) discussed how the soil variability can be linked to complex depositional conditions. Other researchers have investigated and quantified the spatial variability of soil properties (Li \& White, 1987; Soulie et al., 1990; Mostyn \& Soo, 1992; Jaksa et al., 1993; Liu et al., 1993; Wickremesinghe \& Campanella, 1993; DeGroot, 1996).

Geostatistics can provide a useful framework (Magnan, 1982; Favre, 1983; Deplagne \& Bacconet, 1993; Breysse \& Frappa, 1999). Geostatistics, and in particular variograms, has been shown to be a useful technique in assessing the range of correlation of the mechanical parameters. The main problem is data availability. Soulie et al. (1990) used horizontal and vertical variograms to describe the spatial variability of in situ undrained shear strength in a clay deposit.

In addition to soil mechanical properties, some researchers

\footnotetext{
* Institut de Recherche en Génie Civil et Mécanique (GéM), Ecole Centrale de Nantes, France.
}

have worked on stratigraphic variability (Nobre \& Sykes, 1992, Sadki, 2001, Baise \& Higgins, 2003).

Little research work has been done on the effects of stratigraphic and mechanical variability on underground structure design in an urban environment. Ménard (1975) was one of the first geotechnical engineers to adopt a global semi-empirical method for addressing this problem, defining a homogeneity index, which enabled him to estimate the magnitude of differential settlements of foundations, depending on the structural stiffness. Such models have been built in specific cases: shallow foundations (Favre \& Genevois, 1987a, 1987b); embankments (Deplagne \& Bacconet, 1993); urban soils (Jaksa, 1995); trench filling (Barthélémy, 1999); and rigid rafts and flexible hyperstatic structures (Breysse, 2002). These studies are not numerous; the cost of soil investigation is a limiting factor for current geotechnical studies.

Damage as a consequence of soil spatial variability can be evaluated through the sensitivity of the structural response to the change of geotechnical parameter values or by the stochastic finite element method. This last technique was suggested by Cornell (1971) in a general discussion of the applicability of second-moment techniques to linear systems, and was developed by Ditlevsen (1980) for solution by matrix techniques. Stochastic finite element methods have been applied to rock and soil mechanics by Su et al. (1969), Paraseau (1973), Cambou (1975), Baecher \& Ingra (1981) and Mellah (1999).

In this study, we applied the geostatistic and first-order second-moment (FOSM) techniques to the D Line subway in the city of Lyon, a site and a project subjected to special attention, leading to an extensive site investigation based on both laboratory and in situ testing.

There were two main objectives. The first was to analyse the influence of uncertainty in the spatial variability of the soil layer position and thickness (stratigraphy). Based on a large number of in situ tests a geostatistical method called kriging (a common and well-known method, especially in mining activities) was applied in order to determine the mean position of each soil layer and its estimated variance. 
These results were then used in the calculation of the surface settlement, taking the tunnel construction into account. This uncertainty could therefore be expressed in terms of a settlement range, which is of considerable interest to geotechnical engineers.

The second objective was to estimate the influence on the calculated settlements of uncertainty in the mechanical property variability. For this purpose, it was decided to use a stochastic finite element method.

The aim of this study is to propose, by use of some tools (two methods of geostatistical analysis - kriging and a stochastic model - and a simplistic mechanical model) and from a real case history, a first approach to the effects of stratigraphic and mechanical variability on the settlement prediction above a tunnel. Numerical tools were selected and adapted for this study. Quantitative indications on uncertainties and errors related to this type of structure are proposed based on information collected in the site of the D Line extension of the Lyon subway.

\section{SPATIAL VARIABILITY AND ITS EFFECT ON SETTLEMENT PREDICTION \\ Stratigraphic variability}

Input data for geostatistical analysis. This study concerns a section $1000 \mathrm{~m}$ long and $200 \mathrm{~m}$ wide located on the extension of the D Line of the Lyon subway between Gorgede-Loup and Gare de Vaise. The depth of the tunnel varies from $7 \mathrm{~m}$ to $15 \mathrm{~m}$. The geotechnical report contains in-situ and laboratory test data, including 105 drillings, destructive and non-destructive testing, in situ tests in boreholes, standard penetration tests, conventional pressuremeter tests and scissometer tests (Bernat, 1996). In this study, the measurements are assumed to be reliable and the geotechnical analysis proposed by the Centre d'Etude des Tunnels (CETU) to be relevant. Therefore the stratigraphic model provided by this analysis for each drilling point should be in agreement with reality.

The three-dimensional position of the drilling points is shown in Fig. 1. This figure provides qualitative information on the sampling density.

Statistical characterisation of the interfaces. A kriging technique was used to obtain, at any point in the soil, an estimate of the position of the soil layer roof, particularly in an unsampled zone, and to define a variance of this estimate. This technique is an optimal interpolation technique providing a map of errors (Brooker, 1979). The estimate is established by weighting the measurements taken in the vicinity of the studied point. Optimal weighting, namely that which proves to be the most realistic for estimating the elevation, is based on the variogram. This basic statistical
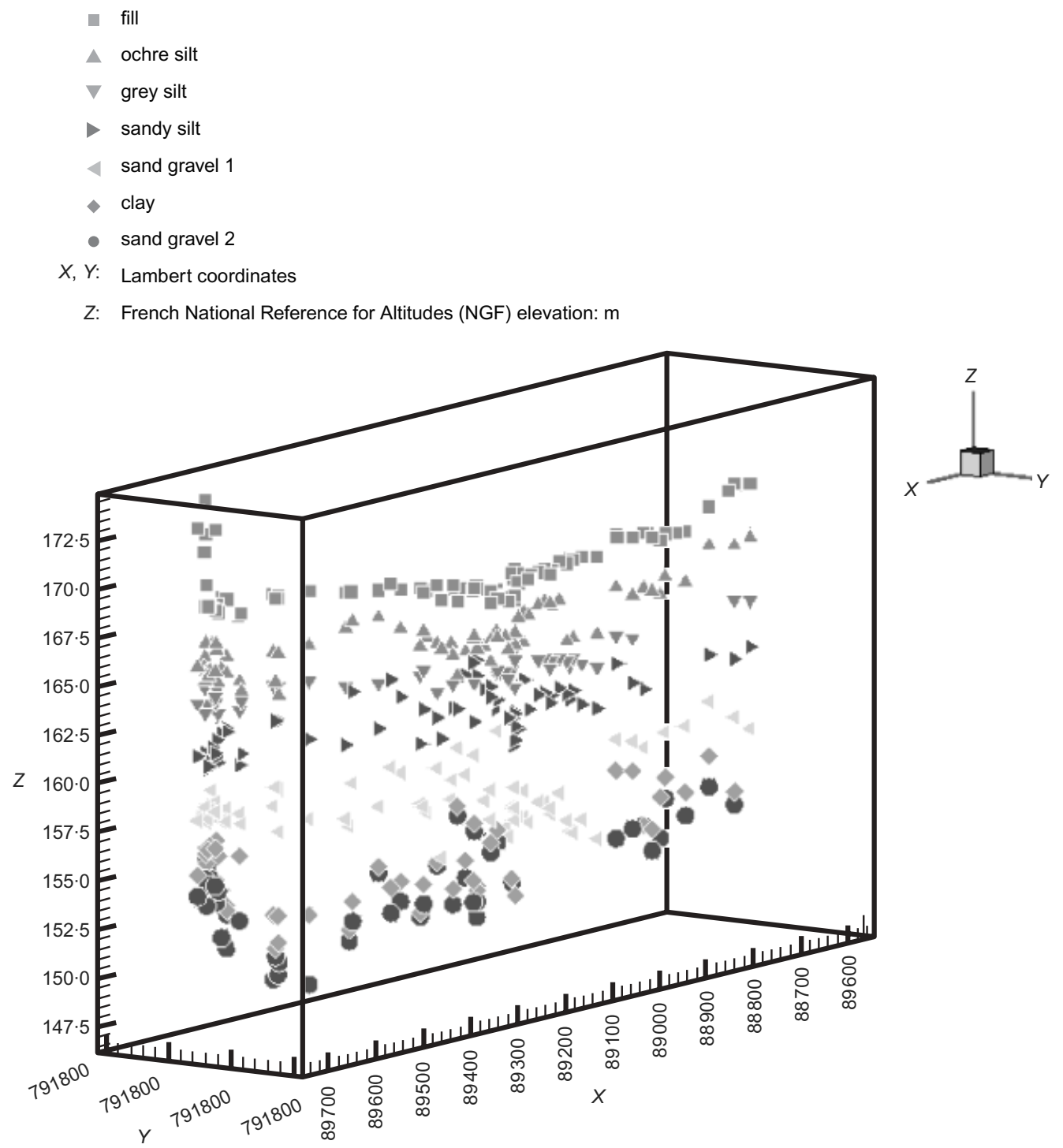

Fig. 1. Drillings and subsurface provided by the geotechnical analysis 
tool gives a structural interpretation of the phenomenon: that is, in the present case, the similarity of the elevation of two points according to the distance that separates them.

The method used in this study is ordinary kriging. This method is based the hypothesised stability of the random function that takes in all the random variables representing the natural variability at any point. Considering the different sections along the axis of the tunnel, this hypothesis seems to be justified over the whole length $(900 \mathrm{~m})$, at least with regard to the four first layers (ochre silt, grey silt, sandy silt and sand gravel 1: see Fig. 2). One can note in particular here that the fluctuations are more important than the drift. By contrast, the two deepest layers (clay and sand gravel 2) show a non-uniform trend, along the support, which could throw doubt on the estimation technique and the evaluation of the variance. Therefore the geostatistical study was applied to two zones $(0-600 \mathrm{~m})$ and $(600-900 \mathrm{~m})$ in order not to integrate the whole depression $(500-800 \mathrm{~m})$ in the natural variability.

Variogram models. All the data concern the elevation of each layer in different sections, so it seemed natural to use this rough information in order to characterise the subsurface profile. However, the profile provided by the kriging of these data can be unrealistic. Owing to the drift of the clay and sand gravel 2 layers, the estimate variance exceeds the thickness of the clay layer. Therefore geostatistical analysis can lead to extreme configurations, with a non-existent clay layer, owing to the overlapping of layers that occurs in some areas. In order to avoid this pattern, a variogram model dealing with the mean position and the thickness of the soil layers is proposed here. These data provide a more realistic representation of the subsurface profile.

The representation of the experimental variogram depends on the lag distance. A sensitivity study was achieved in order to obtain a variogram associating precision and regularity, smoothing the disturbance due to a lack of data. A $25 \mathrm{~m}$ step was found to be the best compromise (Fig. 3).

The variograms related to the first four layers are bound (Fig. 4). This confirms, for these layers, the hypothesis of stationarity expressed previously. The clay and sand gravel 2

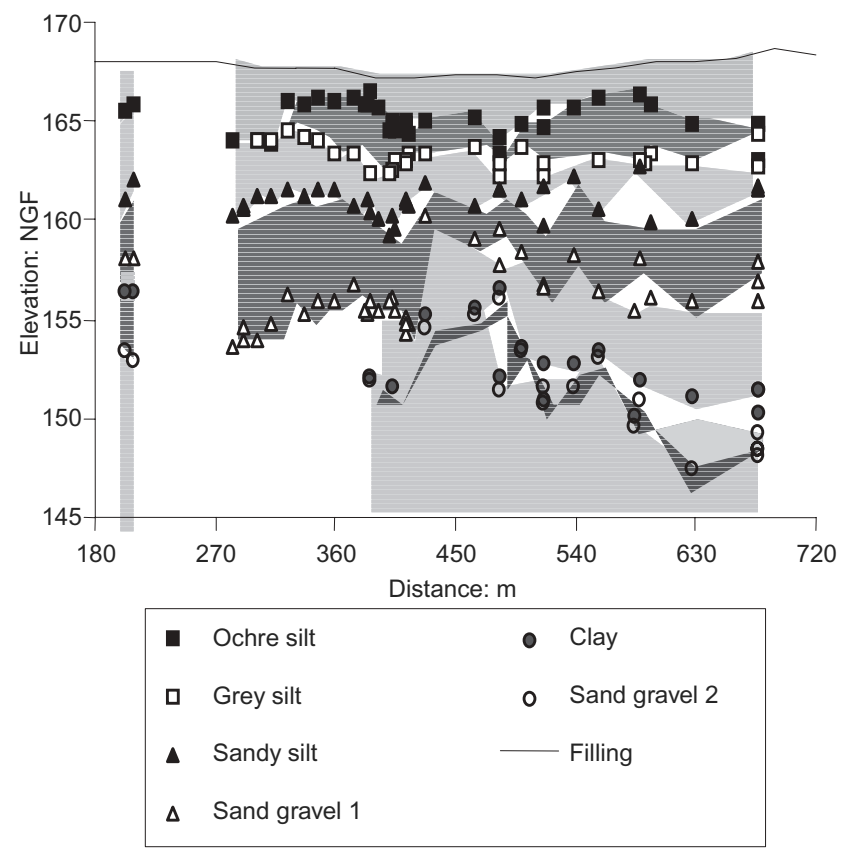

Fig. 2. Subsurface profile of the site in the studied zone: projection on the vertical plane passing by the axis of the tunnel variograms show the typical profile of a signal with a drift. Nevertheless, it was decided to use these variogram structures, and to try to validate them by comparing the kriging results with the measurement data.

These variograms show some irregularities, called the hole effect, due to the lack of information: this is a recurrent problem in geotechnical studies. These irregularities are smaller in cohesive soil layers (embankment, ochre silt and grey silt) than in sandy layers, except for the clay layer located between the two sand gravel layers. Therefore, for an interface between two cohesionless material layers, the variogram representing the mean elevation indicates a less continuous profile, a smaller range and a higher plateau (standard deviation). The two silt layers have a mean position range ${ }^{\dagger}$ varying from 70 to $130 \mathrm{~m}$ and a plateau varying from 0.4 to $0.5 \mathrm{~m}^{2}$. A smaller range (approximately 60$70 \mathrm{~m}$ ) and a significant variability (maximal plateau of 1$2 \mathrm{~m}^{2}$ ) characterise the sandy layers. These ranges justify the method used to assess the subsurface profile and its variance.

Hence there seem to be two different spatial structures, depending on the nature of the soil. No geological interpretation of this phenomenon is proposed here, and the conclusion concerns only a particular site. It would be useful to compare these results with similar analyses carried out in other urban sites.

Kriging method. For the purpose of kriging, correlation structures are determined by fitting typical variogram shapes with mathematical models assuming a positive estimate. Spherical and exponential models were applied in this study (Tables 1 and 2). Cross-validation tests showed that the spherical model was better adapted than the exponential model when considering all the soil layers (Table 3 ).

The kriging result is a series of maps depicting the isovalues of the mean position of each layer and of the variance of this estimate.

Layer elevations and their variances in a $600 \mathrm{~m}$ long zone. On the basis of the previous results, a likely interface zone is then defined as the intersection of zones indicated in Fig. 5.

This process does not take into account the mean position variance, which would have led to a greater uncertainty in the position of the interfaces between layers and to some profile configurations without the clay layer. Based on the geotechnical analysis (Fig. 2), this possibility cannot be justified.

Other processes likely to propose a subsurface profile and its variability can probably be applied. However, this process was selected on account of the conformity of the results with the observations (Fig. 6). Unlike the process dealing with interface data, all the observed layers are represented.

Some measurements are located outside the maximum limits of a given layer. This shows that the kriging process, as with most interpolators, smoothes the profile resulting from measurements. Therefore each zone has to be considered as a 'likely' zone. One can also notice here that the elevation variability is probably underestimated, because the extent of the measured area exceeds the tunnel zone. A weighting of measurements located in the tunnel zone would probably give a more realistic stratigraphy model for calculation purposes.

$\uparrow$ Range: a parameter of a covariance or semivariogram model that represents a distance beyond which there is little or no autocorrelation among variables. 


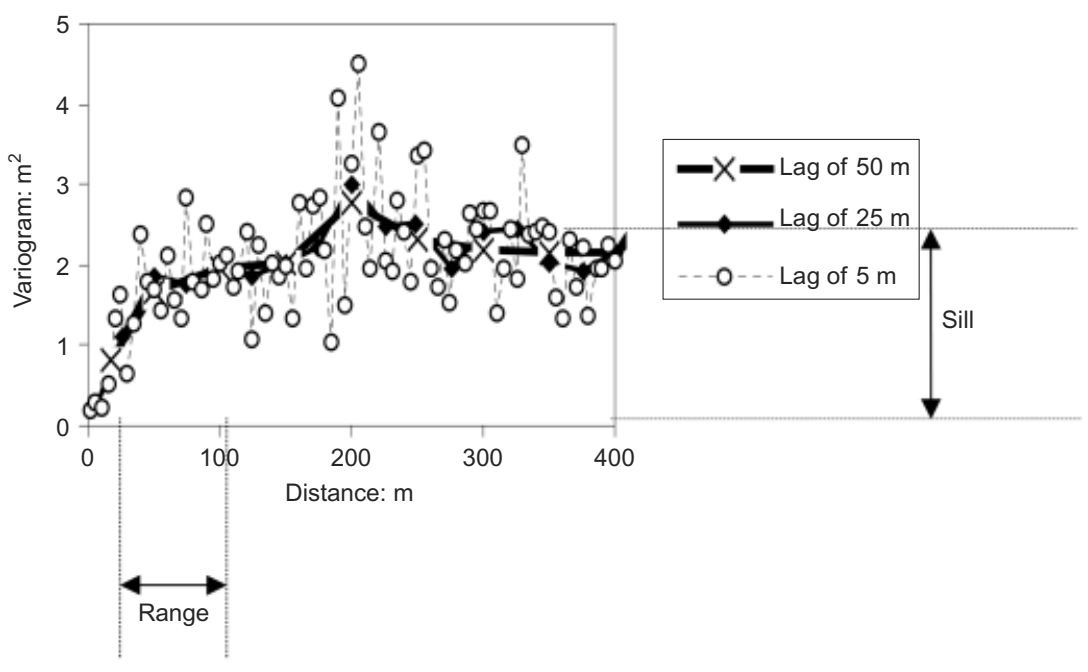

Fig. 3. Variogram from sand gravel 1 layer

Effect of stratigraphy variability on settlement prediction

From the previous geostatistical analysis, 19 cross-sections were defined in a $540 \mathrm{~m}$ long profile, each section including the tunnel position, as indicated in Fig. 6. A two-dimensional numerical modelling of the tunnel excavation has been carried out every $30 \mathrm{~m}$. It turned out that this distance corresponds to one half of the smallest autocorrelation distance $(60 \mathrm{~m})$. This distance between two study zones is therefore considered to be a good compromise between computing time and the accuracy of the results for autocorrelation distance. The numerical results related to the 19 sections are presented. In each cross-section, each soil layer interface is supposed to be horizontal. This hypothesis can be justified by the diameter of the tunnel $(6 \mathrm{~m})$, which represents only one tenth of the smallest range.

For each of the 19 cross-sections, and for all extreme positions (lower and upper limits) of the interfaces, a numerical calculation of the surface settlement was performed. Thus, in the 19 cross-sections, the tunnel position varies according to Fig. 6. The numerical model is defined as follows:

(a) Calculation by the finite element method (calculation code: Cesar-LCPC).

(b) 2D calculation (plane strain), lower limit of the field located at $8 \mathrm{~m}$ under the tunnel invert, half the width $=$ $38 \mathrm{~m}$ (Fig. 7(a)) ${ }^{\dagger}$

(c) The mesh (Fig. 7(b)) consists of 2995 quadratic triangular elements (T6) and 6144 nodes.

(d) The constitutive relationship for the soil is an elastic, perfectly plastic, non-associated Mohr-Coulomb model. The set of parameters is given in Table 4. It is a reference set proposed in a previous study by Riou et al. (2000). These values are mean values, determined

$\dagger$ The heave at the tunnel invert depends on this distance when the Mohr-Coulomb model is used with a constant Young's modulus: so this distance is fixed.

\$ Such an elastic perfectly plastic analysis is generally not appropriate for the modelling of tunnel excavation, unless attention is paid to the parameter assessment in the different parts of the soil mass (these arrangements will be introduced later). However, we consider for this purpose of comparison that the model does not affect the variance of the surface settlement related to stratigraphic variability. Table 4 shows abnormally high or low values of the dilatancy angle. These parameters, based on laboratory tests, have been maintained and were not subjected to modifications. from analysis of triaxial tests performed on each type of soil.

(e) An effective-stress calculation has been performed, so the hydraulic pressure on the tunnel boundary is assumed equal to the hydraulic pressure in the field.

$(f)$ The constitutive relationship for the tunnel lining is linear elastic behaviour, with thickness $0.35 \mathrm{~m}$, mean radius $2.82 \mathrm{~m}$, and Young's modulus $13500 \mathrm{MPa}$.

$(g)$ Boring is modelled in three stages: stage 0 , setting of the initial stress state $\left(K_{0}=0 \cdot 5\right)$; stage 1 , partial force release at the outside line of the tunnel up to a ratio $\lambda$ (no lining); stage 2, complete force release with lining.

(h) The effective unit weight of the tunnel is $-3 \cdot 2 \mathrm{kN} / \mathrm{m}^{3}$.

(i) $\lambda$ was taken equal to $32 \cdot 5 \%$. The assessment of the value chosen for $\lambda$ was based on a comparison between numerical results and in-situ data in a reference section. ${ }^{\S}$

The lower and upper limits of the surface settlement in the 19 sections are shown in Fig. 8.

The sensitivity analysis based on the calculated surface settlements gives a maximum scattering of $63 \%$ (32\%, if only stage 1 is taken into consideration). Concerning stage 1 , the analysis of the results showed that this scattering depends on the thickness and type of soil. This result seems consistent, as the unloading due to the force release acts mainly on these layers. The scattering of the total surface settlement (end of stage 2) is more difficult to analyse because of the tunnel upheaval due to the hydrostatic pressure acting on the lining, which also has an effect on the layers adjacent to the tunnel.

The variation of the calculated surface settlements in the 19 sections along the $540 \mathrm{~m}$ long zone integrates the changes in the tunnel position, governed not only by stratigraphic considerations but also by practical requirements. These calculated values have to be compared with the recorded surface settlements ranging from 2 to $11 \mathrm{~mm}$. However, it should be noted that this range includes not only the stratigraphic uncertainties, but also uncertainties in the soil mechanical properties and in the tunnel boring conditions.

A statistical analysis of the surface settlement, depending on the tunnel position and the stratigraphy, and calculated in

$\S$ As mentioned in the Introduction, the aim of this study is a sensitivity analysis on the error caused by the natural variability of the subsurface in urban sites. With this in mind, it was decided to keep $\lambda$ constant. 


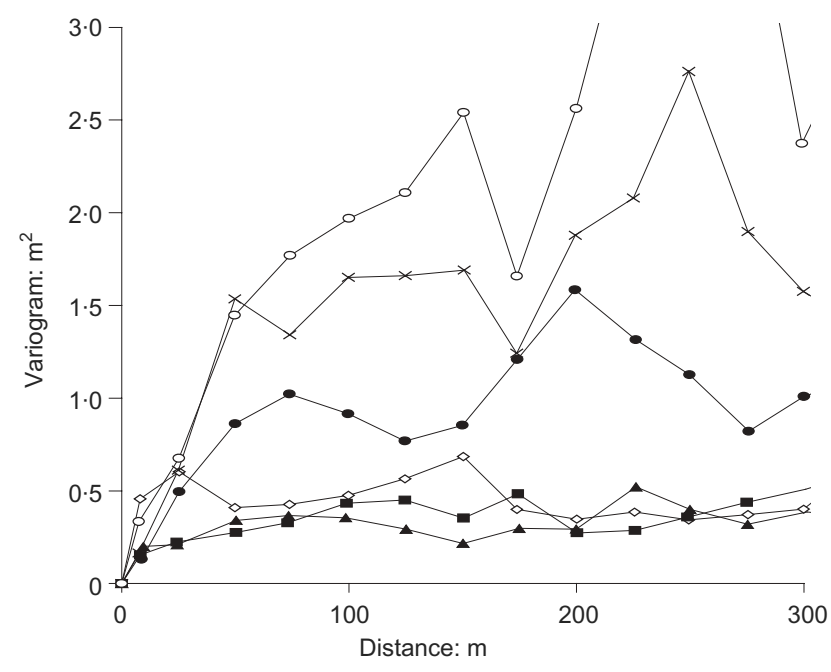

Table 2. Sets of models tested for thickness variograms

\begin{tabular}{l|c|c|c}
\hline Soil layer & Diagram & Range: $\mathrm{m}$ & Sill: $\mathrm{m}^{2}$ \\
\hline Embankment & & & \\
Ochre silt & $\mathrm{S}+\mathrm{E}$ & $30-50$ & $0 \cdot 5$ \\
Grey silt & $\mathrm{S}+\mathrm{E}$ & $30-50$ & $0 \cdot 5$ \\
Sandy silt & $\mathrm{S}+\mathrm{E}$ & $50-60$ & $2 \cdot 3$ \\
Sand gravel 1 & $\mathrm{S}+\mathrm{E}$ & $100-120$ & $4 \cdot 2$ \\
Clay & $\mathrm{S}+\mathrm{E}$ & $30-50$ & $0 \cdot 40$
\end{tabular}

$\mathrm{S}=$ Spherical model, $\mathrm{E}=$ Exponential model

Table 3. Results of the cross-validation

\begin{tabular}{l|c|c|c|c}
\hline \multirow{2}{*}{$\begin{array}{l}\text { Soil layer } \\
\text { layer }\end{array}$} & \multicolumn{2}{|c|}{ Select layer } & $\begin{array}{c}\text { Errors } \\
\text { estimate: } \mathrm{m}\end{array}$ & $\begin{array}{c}\text { Error } \\
\text { variance: } \mathrm{m}^{2}\end{array}$ \\
\cline { 2 - 3 } & Model & Range: $\mathrm{m}$ & & \\
\hline Ochre silt & $\mathrm{S}$ & 90 & $0 \cdot 021$ & $0 \cdot 164$ \\
Grey silt & $\mathrm{S}$ & 80 & $0 \cdot 036$ & $0 \cdot 13$ \\
Sandy silt & $\mathrm{S}$ & 60 & $0 \cdot 0215$ & $0 \cdot 41$ \\
Sand gravel 1 & $\mathrm{S}$ & 60 & $0 \cdot 006$ & $0 \cdot 88$ \\
Clay & $\mathrm{S}$ & 70 & $0 \cdot 027$ & 1 \\
\hline
\end{tabular}

(a)
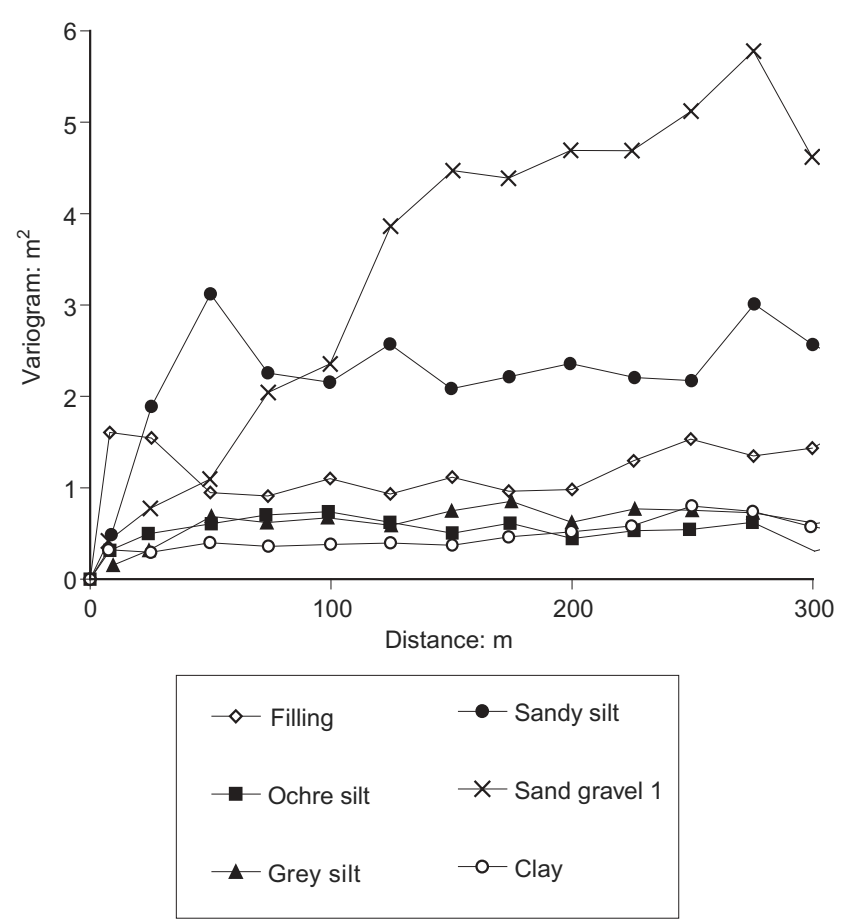

(b)

Fig. 4. Variograms of (a) mean position and (b) thickness of the layers

Table 1. Sets of models tested for mean position variograms

\begin{tabular}{l|l|l|l}
\hline Soil layer & Diagram & Range: $\mathrm{m}$ & Sill: $\mathrm{m}^{2}$ \\
\hline Embankment & & & \\
Ochre silt & $\mathrm{S}+\mathrm{E}$ & $70-130$ & $0 \cdot 4$ \\
Grey silt & $\mathrm{S}+\mathrm{E}$ & $70-130$ & $0 \cdot 3$ \\
Sandy silt & $\mathrm{S}+\mathrm{E}$ & $60-70$ & $0 \cdot 85$ \\
Sand gravel 1 & $\mathrm{S}+\mathrm{E}$ & $60-70$ & $1 \cdot 65$ \\
Clay & $\mathrm{S}+\mathrm{E}$ & $60-70$ & $2 \cdot 00$ \\
\hline
\end{tabular}

$\mathrm{S}$, spherical model; E, exponential model.

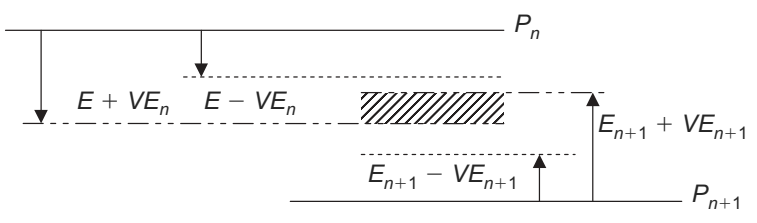

Fig. 5. Assessment of 'likely interface zone': $P_{n}$, estimate of layer $n$ mean position; $E_{n}$, estimate of layer $n$ half-thickness; $V E_{n}$, variance of layer $n$ half-thickness

each section $30 \mathrm{~m}$ distant from each other, leads to a pseudo structure of these estimates. The variogram of this calculated settlement (Fig. 9) is characterised by a autocorrelation distance of approximately $200 \mathrm{~m}$. Considering that, in this particular case, the autocorrelation distance of the stratigraphic structure is approximately $60 \mathrm{~m}$, a tunnel layout well suited to stratigraphic structure can smooth this natural variability in a ratio of $1: 3$ in terms of autocorrelation distance.

\section{SPATIAL VARIABILITY OF SOIL MECHANICAL PROPERTIES AND EFFECT ON CALCULATED SETTLEMENTS}

A preliminary study on some transverse sections of this underground works has demonstrated that an elastic model, in some ways and with appropriate parameters (especially distinct Young's moduli for loading and unloading conditions), can produce acceptable results. The plastic zones induced by the tunnelling process have limited extent. A sensitivity study has been carried out on the soil parameters, and shows a weak influence on the settlement (Fig. 10). Thus, in this particular case, the elastic parameters are the prime parameters in a settlement calculation during the tunnel excavation, whereas the failure parameters - cohesion and friction angle-play a minor role in the amplitude of the surface settlement.

We focused our study on the spatial variability of the elastic properties. For this purpose, most of the available data came from in situ pressuremeter tests. From the socalled pressiometric moduli, we derived the values of Young's moduli that were entered into the numerical calculations. 


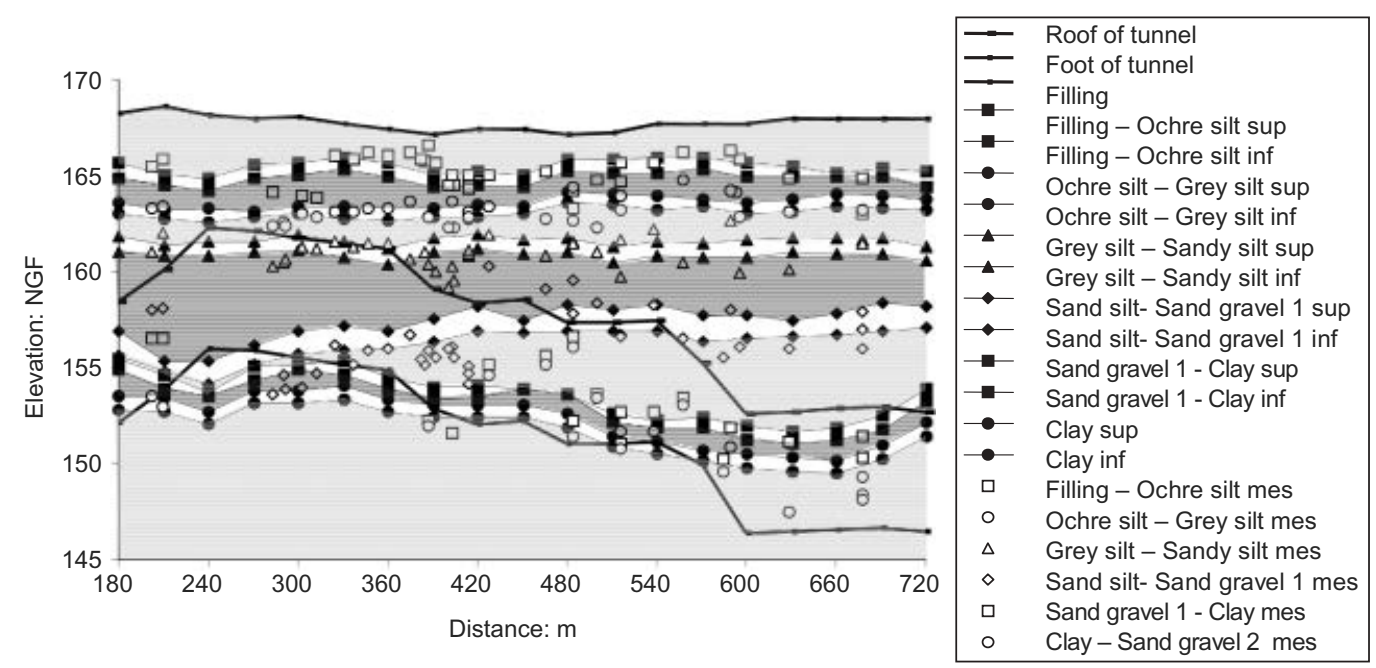

Fig. 6. Measures and geostatistical subsurface

\section{Spatial variability of pressiometric modulus measured in loading and unloading}

The horizontal variability of the pressiometric modulus values during loading and unloading stages was at first analysed using the kriging method in order to propose an estimation of the pressiometric modulus and its variance at any point. The variograms established for each layer on the basis of the mean values relative to the same depth were shown to be unusable. It was therefore not possible to come out with an autocorrelation distance and a sill (Fig. 11). One could also note the systematic presence of a strong nugget effect, which seemed to indicate an apparent discontinuity at the origin. This nugget effect was probably also due to an inadequate number of values, and to measurement errors.

From the results obtained with the variograms, it was not reasonable to propose autocorrelation distances, and only the variances were used. Thus one could define a maximum variance of $10 \mathrm{MPa}^{2}$ for the clay layer modulus and of $30 \mathrm{MPa}^{2}$ for the fill layer modulus during a loading phase, and of $200 \mathrm{MPa}^{2}$ and $250 \mathrm{MPa}^{2}$ respectively for the moduli measured during an unloading phase.

The silt layers were characterised by a maximum variance of $15-20 \mathrm{MPa}^{2}$ for the pressiometric moduli measured during a loading phase, and by a maximum variance of 150 $200 \mathrm{MPa}^{2}$ for the pressiometric moduli in unloading. The layers containing a sandy fraction were characterised by a greater variability: a maximum variability of $50-70 \mathrm{MPa}^{2}$ for the moduli in loading and of $300-400 \mathrm{MPa}^{2}$ for the moduli in unloading. It was observed generally that the variability of the pressiometric moduli was less pronounced in layers of cohesive materials than in those of sandy materials.

\section{Effect of soil mechanical property variability on predicted settlements}

The pressiometric moduli were transformed into Young's moduli in order to suit the needs of the numerical calculation using the finite element method. We decided to adapt the Young's modulus values according to the different stress paths acting in the ground. During the excavation, the soil located at the crown and at the invert of the tunnel is subjected to an unloading, while the soil located at the sides of the tunnel is subjected to a loading (Fig. 12). Therefore, in order to create a numerical model that conforms more accurately to the reality, the following elastic moduli were considered: unloading moduli for the soil layers situated at the crown and invert of the tunnel, and loading moduli for the layers situated at the side.

The statistical characteristics of the material stiffness were defined in the six zones identified in the Lyon site (Fig. 13). This subdivision of the site can be justified in the sense that, in every zone considered, the test density is high, and the position of the tunnel can be considered as constant.

In order to determine these soil characteristics, we focused on the experimental results relative to each of these zones, and on the numerical results, which pointed out precisely the different stress paths followed by the soil masses around the tunnel. For each soil layer, the modulus value was taken as equal to the mean value determined from a loading or an unloading stage (Table 5).

For each zone defined in Fig. 13, a numerical calculation was performed, which gave the surface settlement in the axis of the tunnel and its variance. This calculation was carried out by applying the following model:

(a) calculation by the finite stochastic element method (calculation code: Probef-LCPC)*

(b) 2D calculation: half the width $=38 \mathrm{~m}$ except in zone 1 , an asymmetric zone characterised by a fill layer supported by a retaining wall; in this zone the width is equal to $76 \mathrm{~m}$

(c) mesh: 1280 nodes; 2413 linear triangular elements

(d) soil model: linear elasticity

(e) excavation modelling: only the first construction phase was considered after the determination of the initial stress state $\left(K_{0}=0 \cdot 5\right)$.

The reference value for the deconfinement ratio $\lambda$ was established by fitting the calculated values to the measured values in zone 1: a value of $\lambda=32.5 \%$ was determined. This value, as well as the initial stress state, was considered constant along the whole layout. Indeed, one can consider that, in the whole layout, the ratio and the direction of the initial principal stresses in the soil do not undergo changes sufficient to influence the calculation results. However, one may think that the coefficient $\lambda$, which partly integrates

\footnotetext{
* The second part of this study rests on a stochastic finite element analysis program (Probef) developed by the Laboratoire Central des Ponts et Chaussées and based on work by Baecher \& Ingra (1981). Probef was used by Boulefkhad (1986) to evaluate the effect of the autocorrelation distance on the uncertainty of the maximum settlement of a flexible foundation.
} 


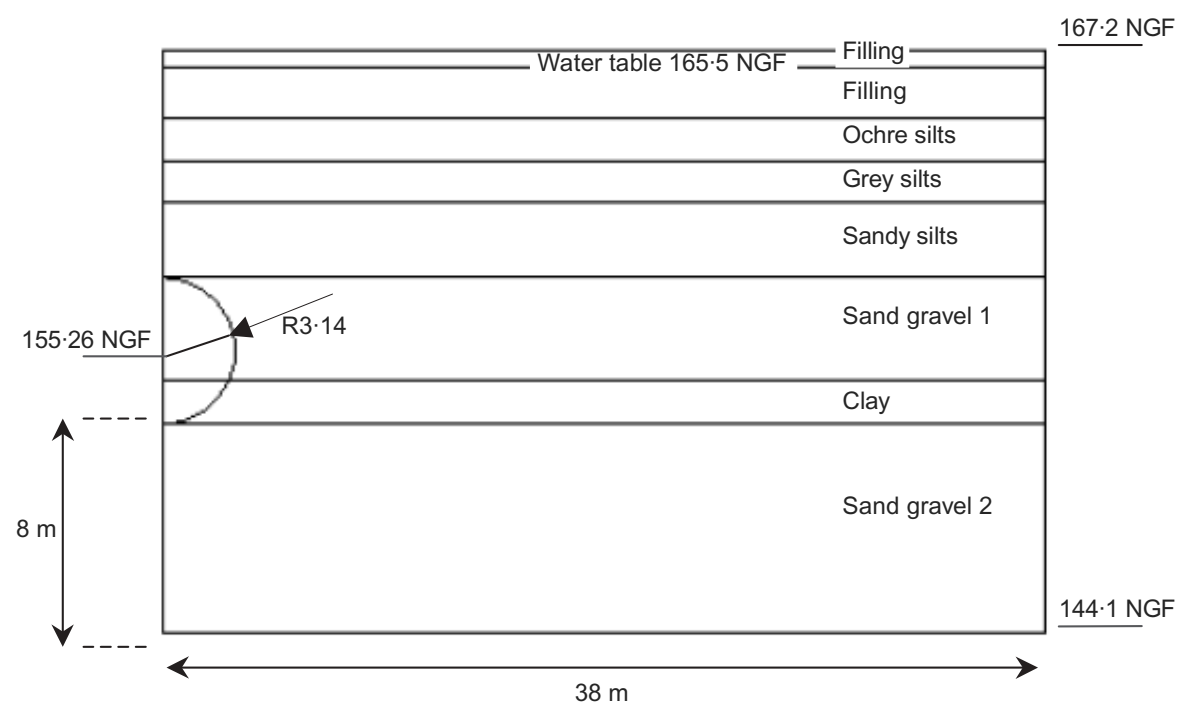

(a)

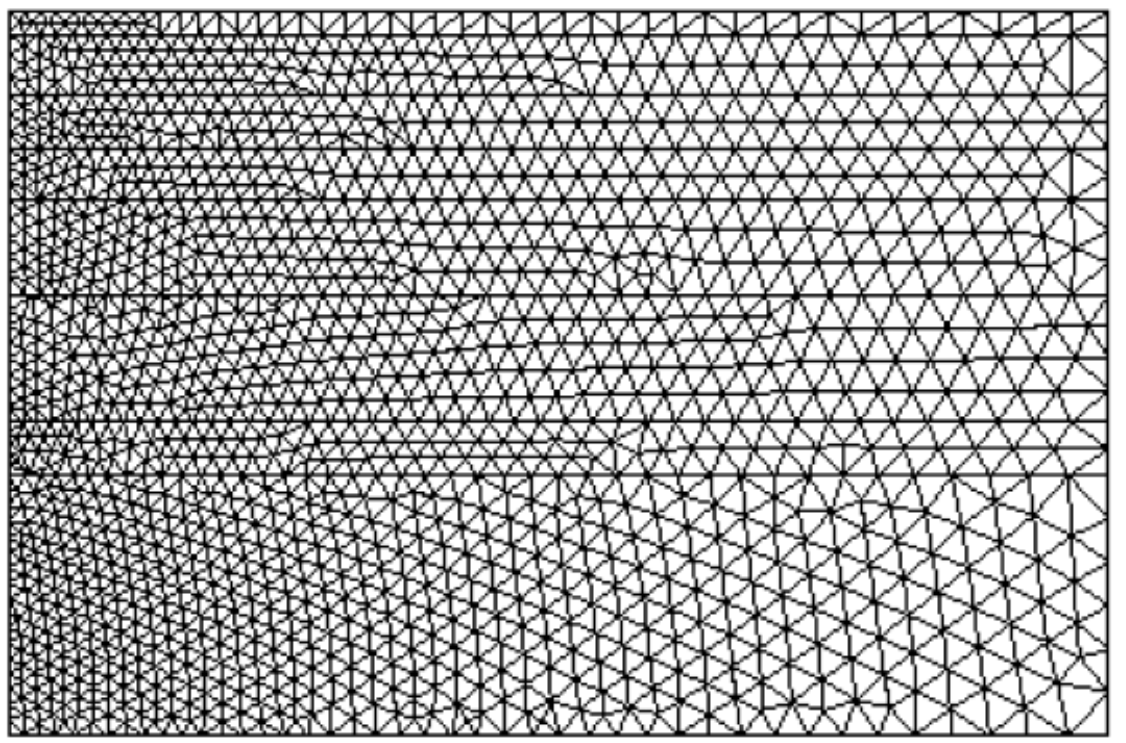

(b)

Fig. 7. (a) Geometrical characteristics of cross-section 450; (b) finite element method mesh

Table 4. Mechanical parameters of subsurface materials

\begin{tabular}{l|c|c|c|c|c|c}
\hline Layer & $E: \mathrm{MN} / \mathrm{m}^{2}$ & $\gamma: \mathrm{kN} / \mathrm{m}^{3}$ & $v$ & $c: \mathrm{kPa}$ & $\phi: \operatorname{deg}$ & $\psi: \operatorname{deg}$ \\
\hline Filling & $11 \cdot 2$ & $18 \cdot 0$ & $1 / 3$ & 30 & 38 & 18 \\
Ochre silt & $15 \cdot 0$ & $20 \cdot 3$ & $1 / 3$ & 15 & 36 & 16 \\
Grey silt & $15 \cdot 0$ & $16 \cdot 3$ & $1 / 3$ & 50 & 22 & 2 \\
Sand gravel 1 & $47 \cdot 7$ & $21 \cdot 0$ & $1 / 3$ & 5 & 35 & 15 \\
Clay & $16 \cdot 9$ & $18 \cdot 4$ & $1 / 3$ & 14 & 20 & 1 \\
Sand gravel 2 & $47 \cdot 7$ & $21 \cdot 0$ & $1 / 3$ & 5 & 35 & 15 \\
\hline
\end{tabular}

Water level: $165 \cdot 5 \mathrm{NGF}$

the digging conditions, is not necessarily constant during the entire layout. In particular, it depends on: the pressure of the lateral grout injections, which varies with the soil resistance; on the drilling rate; on possible incidents during the course of the drilling (drilling starts and stops); on the pressure at the working face, which is not always well controlled; on layout curvatures; and on different site configurations (thickness of the covert, surface profile). In the absence of a refitting in conditions similar to those corresponding to the study realised in zone 1, it was difficult to correct the values of this coefficient in each zone. Therefore $\lambda$ was kept constant for the entire layout.

Two positions of the tunnel were considered. The first was a constant position for the whole length of the layout, corresponding to the mean position of the tunnel. In this case, the loading condition in the soil was almost constant, which allowed us to draw some conclusions concerning the influence of the two intrinsic variabilities of the site (strati- 


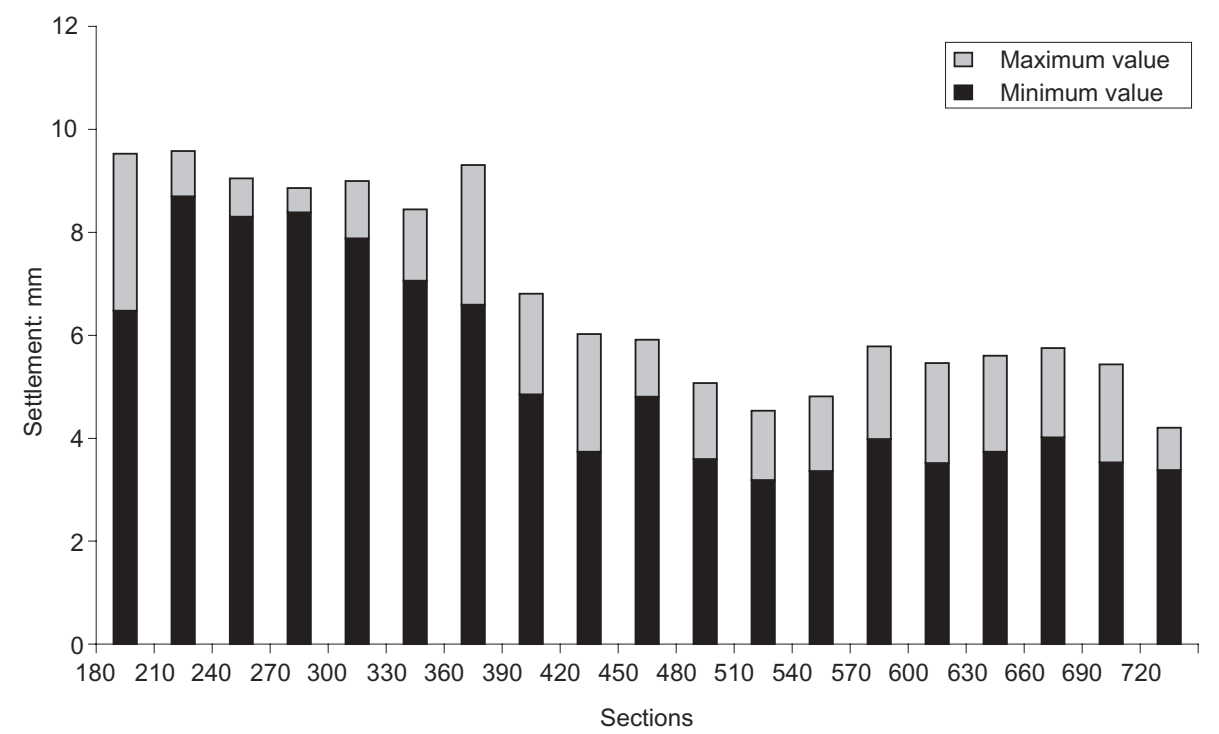

(a)

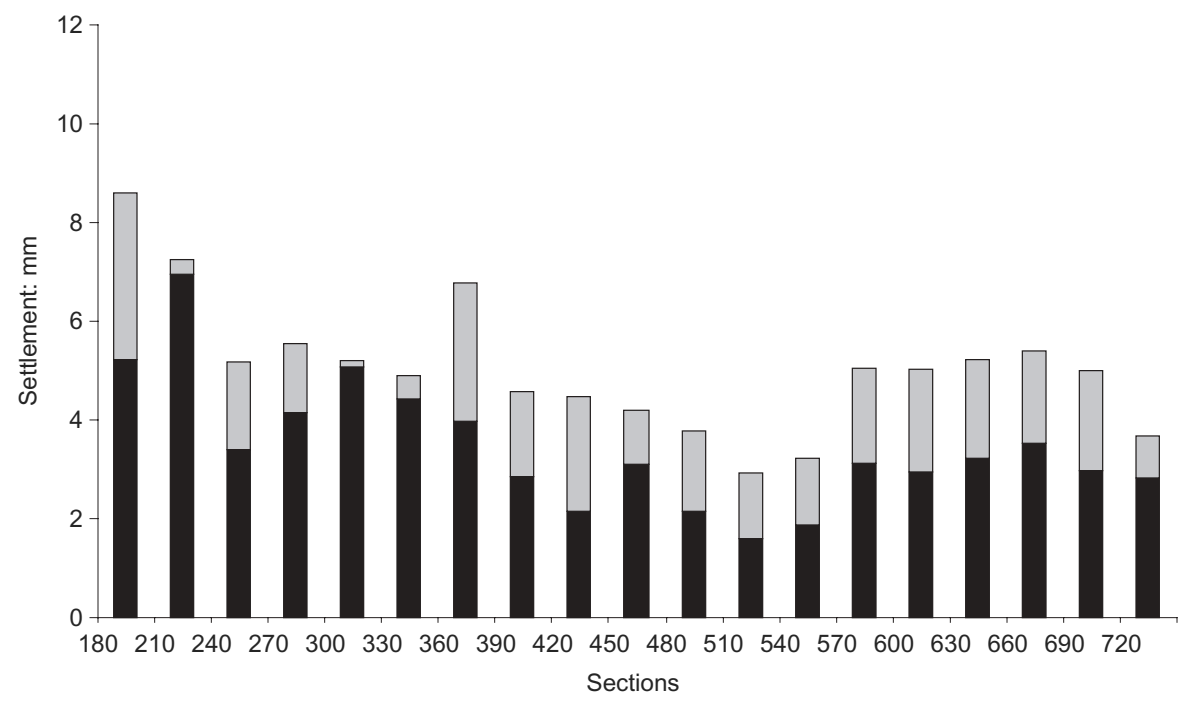

(b)

Fig. 8. Variation of surface settlement in the 19 sections: (a) end of stage 1; (b) end of stage 2

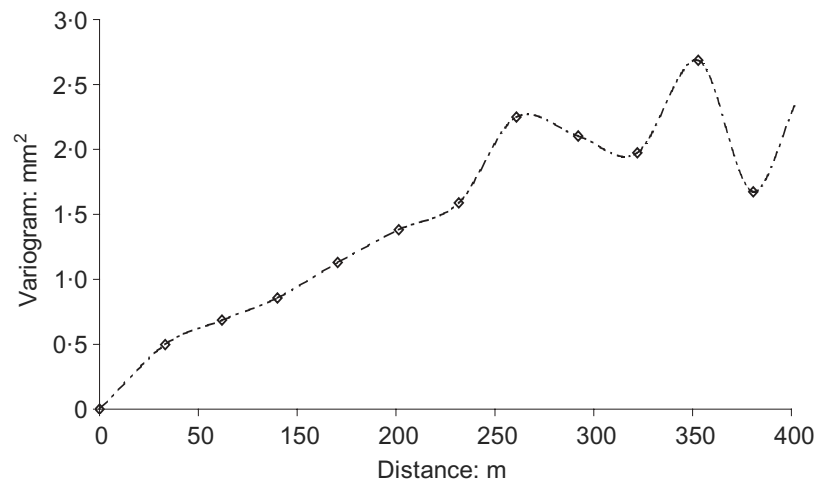

Fig. 9. Variogram of surface settlement

graphic and mechanical properties variability) on the prediction of the surface settlement.

The second was the real position of the tunnel. The purpose here was to estimate the variance of the surface settlements by integrating, as well as the stratigraphic and mechanical properties variability, the different possible positions of the tunnel in an urban context.

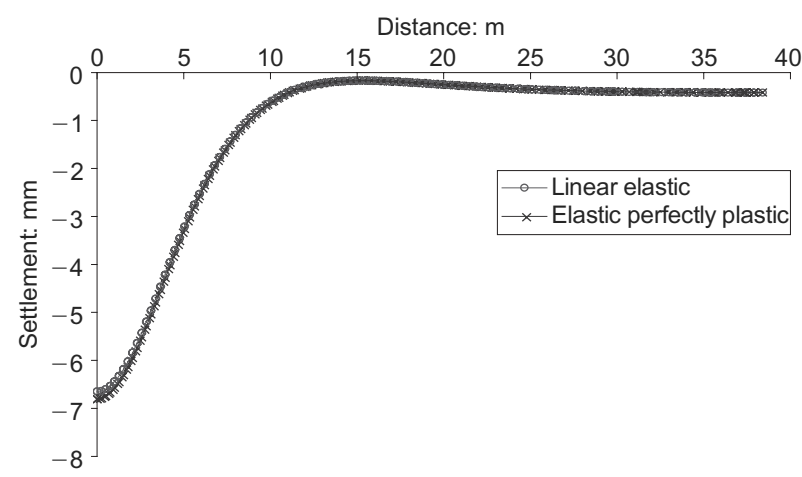

Fig. 10. Surface settlement calculated for section 360 at end of stage 2

The results presented above do not demonstrate the existence a particular structure of the mechanical properties of the different soil layers (no autocorrelation distance for the parameter values). This can be the result of a 'natural destructuration' of the soil, of a remoulding during testing, or of a lack of measurement accuracy in these tests. Taking 


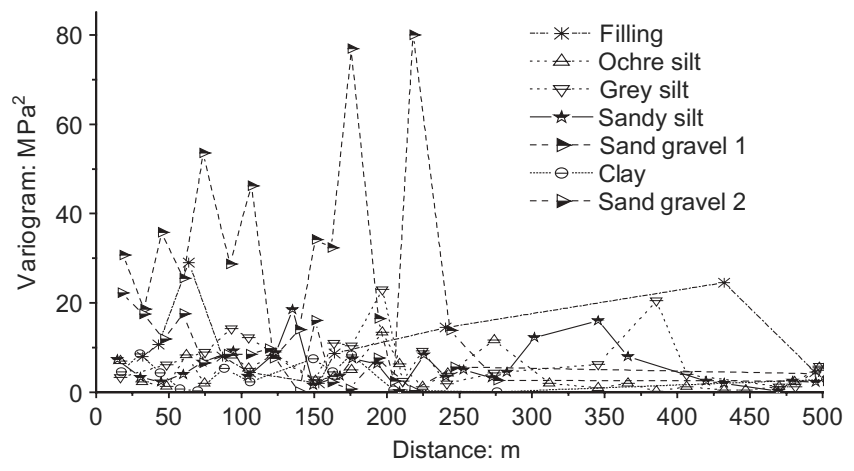

Fig. 11. Variograms established for each layer on the basis of mean values relative to the same depth

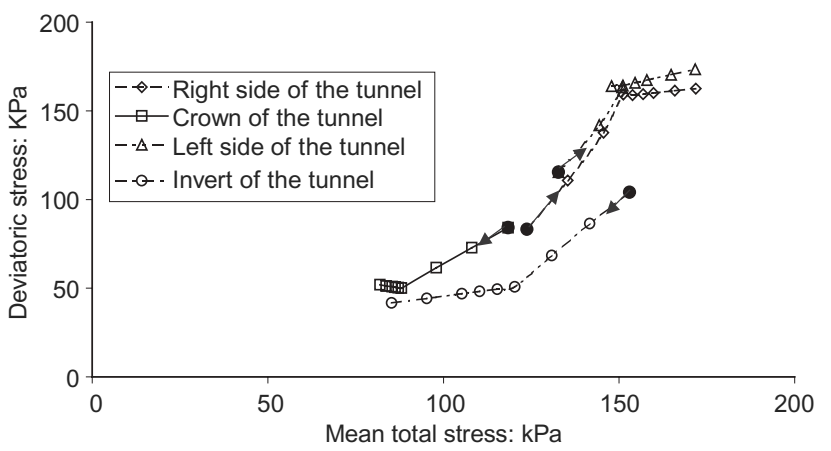

Fig. 12. Stress path of stress followed by the four points of the tunnel into account that a (non-justified) weak autocorrelation distance (or no autocorrelation distance) would result in a minimisation of the standard deviation of surface settlement, and in order to assess the sensitivity of this distance on the calculated settlement, we considered an autocorrelation distance of the mechanical properties equal to the stratigraphic autocorrelation distance for each layer.

The predictions of the surface settlements as well as the variances calculated in the six zones are given in Fig. 14. An analysis of these results leads to the following remarks:

(a) For loading conditions of the soil that are almost identical along the whole layout (i.e. for a constant mean position of the tunnel) the predictions of the surface settlements vary between $4.5 \mathrm{~mm}$ and $19.7 \mathrm{~mm}$ from zone 1 to zone 6 . This evolution is regular along the whole layout. The strongest gradient is equal to $0.07 \mathrm{~mm} / \mathrm{m}$. This variation from zone 1 to zone 6 is not linked to a stratigraphic change in the layers where the tunnel was installed (layers of sand gravel 1, clay and sand gravel 2). In fact, it is due partly to the variability of the Young's modulus in the clay and fill layers, which was found to be three times higher in zone 6 than in zone 1 , and partly to the change in thickness of the fill layer.

(b) The maximum uncertainty in the surface settlement in a given zone (coefficient of variation) is of the order of $10 \cdot 3 \%$ when the autocorrelation distance is zero. This variance coefficient can appear small in comparison with the variance coefficients determined for the stiffness of the different soil layers $(10-80 \%)$. This small value is explained by the fact that we considered

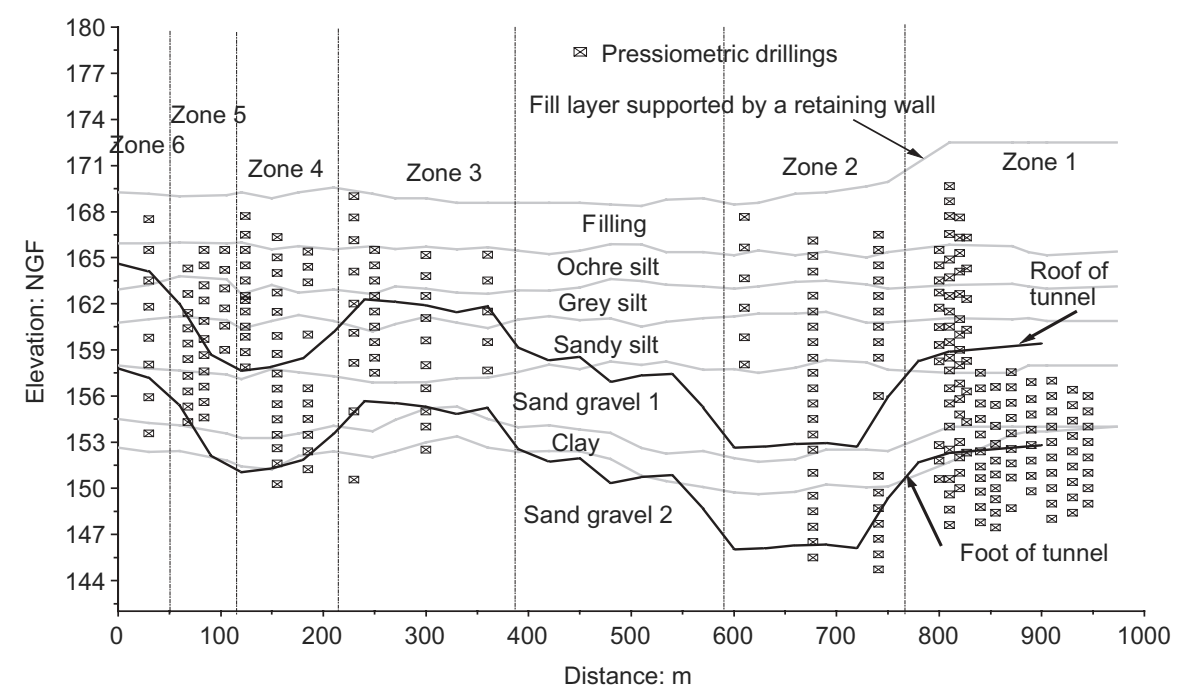

Fig. 13. Sets of zones considered for determination of elastic characteristics

Table 5. Stochastic characteristics of the stiffness of the soil

\begin{tabular}{|c|c|c|c|c|c|c|c|c|c|c|c|c|}
\hline \multirow[t]{2}{*}{ Layer } & \multicolumn{2}{|c|}{ Zone 1} & \multicolumn{2}{|c|}{ Zone 2} & \multicolumn{2}{|c|}{ Zone 3} & \multicolumn{2}{|c|}{ Zone 4} & \multicolumn{2}{|c|}{ Zone 5} & \multicolumn{2}{|c|}{ Zone 6} \\
\hline & $\begin{array}{r}E_{\mathrm{el}}: \\
\mathrm{MPa}\end{array}$ & $\begin{array}{r}\mathrm{CV} \\
\left(E_{\mathrm{el}}\right)\end{array}$ & $\begin{array}{r}E_{\mathrm{el}}: \\
\mathrm{MPa}\end{array}$ & $\begin{array}{r}\mathrm{CV} \\
\left(E_{\mathrm{el}}\right)\end{array}$ & $\begin{array}{r}E_{\mathrm{el}}: \\
\mathrm{MPa}\end{array}$ & $\begin{array}{r}\mathrm{CV} \\
\left(E_{\mathrm{el}}\right)\end{array}$ & $\begin{array}{r}E_{\mathrm{el}}: \\
\mathrm{MPa}\end{array}$ & $\begin{array}{r}\mathrm{CV} \\
\left(E_{\mathrm{el}}\right)\end{array}$ & $\begin{array}{r}E_{\mathrm{el}}: \\
\mathrm{MPa}\end{array}$ & $\begin{array}{r}\mathrm{CV} \\
\left(E_{\mathrm{el}}\right)\end{array}$ & $\begin{array}{r}E_{\mathrm{el}}: \\
\mathrm{MPa}\end{array}$ & $\begin{array}{r}\mathrm{CV} \\
\left(E_{\mathrm{el}}\right)\end{array}$ \\
\hline Filling & $3 \cdot 7$ & 0.7 & $5 \cdot 0$ & $0 \cdot 4$ & $15 \cdot 0$ & 0.5 & $7 \cdot 9$ & 0.4 & $7 \cdot 9$ & $0 \cdot 4$ & $14 \cdot 7$ & 0.4 \\
\hline Ochre silt & $6 \cdot 2$ & $0 \cdot 6$ & 11.9 & $0 \cdot 5$ & $10 \cdot 0$ & $0 \cdot 2$ & $10 \cdot 35$ & $0 \cdot 4$ & $8 \cdot 7$ & $0 \cdot 4$ & $13 \cdot 6$ & $0 \cdot 4$ \\
\hline Grey silt & $6 \cdot 2$ & $0 \cdot 6$ & $11 \cdot 55$ & $0 \cdot 3$ & $6 \cdot 5$ & $0 \cdot 4$ & $10 \cdot 5$ & $0 \cdot 2$ & $12 \cdot 0$ & $0 \cdot 4$ & $24 \cdot 0$ & $0 \cdot 1$ \\
\hline Sandy silt & $6 \cdot 2$ & $0 \cdot 6$ & $9 \cdot 5$ & $0 \cdot 4$ & $6 \cdot 3$ & $0 \cdot 3$ & $13 \cdot 4$ & $0 \cdot 2$ & $12 \cdot 0$ & $0 \cdot 2$ & $13 \cdot 9$ & $0 \cdot 1$ \\
\hline Sand gravel 1 & $44 \cdot 5$ & $0 \cdot 4$ & $23 \cdot 3$ & $0 \cdot 3$ & $32 \cdot 9$ & $0 \cdot 4$ & $47 \cdot 25$ & $0 \cdot 3$ & $69 \cdot 3$ & $0 \cdot 4$ & $44 \cdot 0$ & $0 \cdot 4$ \\
\hline Clay & $5 \cdot 1$ & $0 \cdot 4$ & $7 \cdot 0$ & $0 \cdot 5$ & $6 \cdot 25$ & $0 \cdot 1$ & $7 \cdot 3$ & $0 \cdot 3$ & $7 \cdot 3$ & $0 \cdot 3$ & $16 \cdot 7$ & $0 \cdot 3$ \\
\hline Sand gravel 2 & $10 \cdot 4$ & $0 \cdot 8$ & $40 \cdot 0$ & $0 \cdot 5$ & $39 \cdot 0$ & $0 \cdot 4$ & $36 \cdot 9$ & $0 \cdot 7$ & $36 \cdot 9$ & $0 \cdot 7$ & $44 \cdot 0$ & $0 \cdot 4$ \\
\hline
\end{tabular}




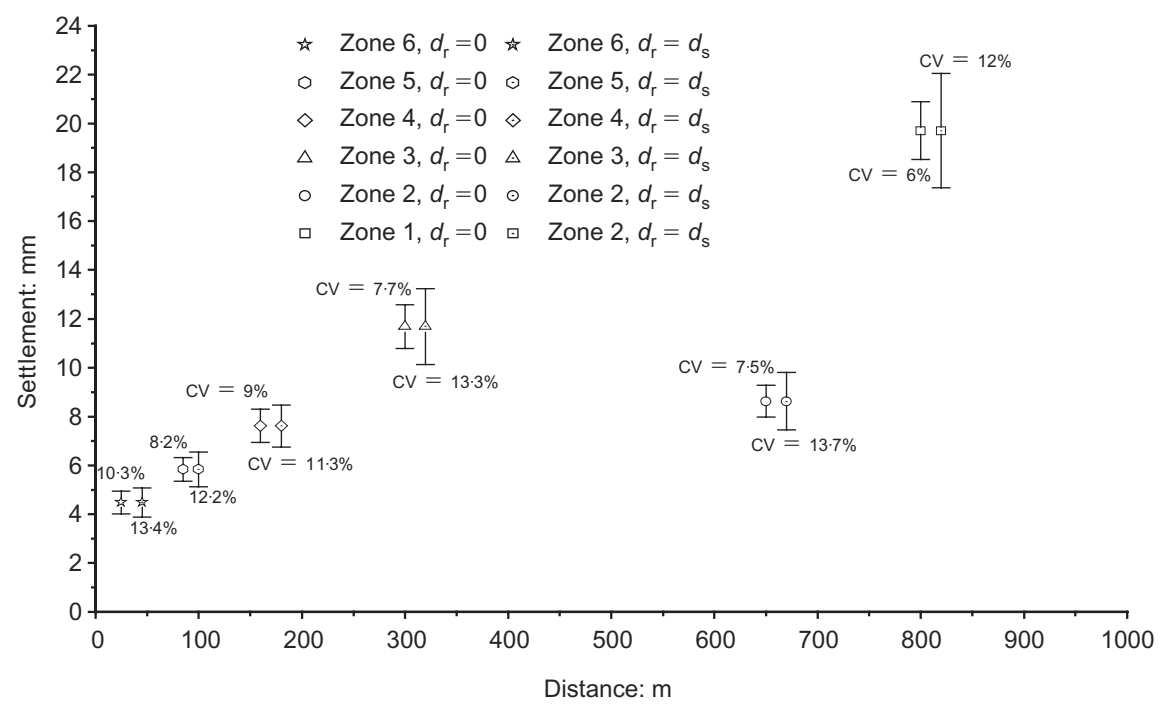

(a)

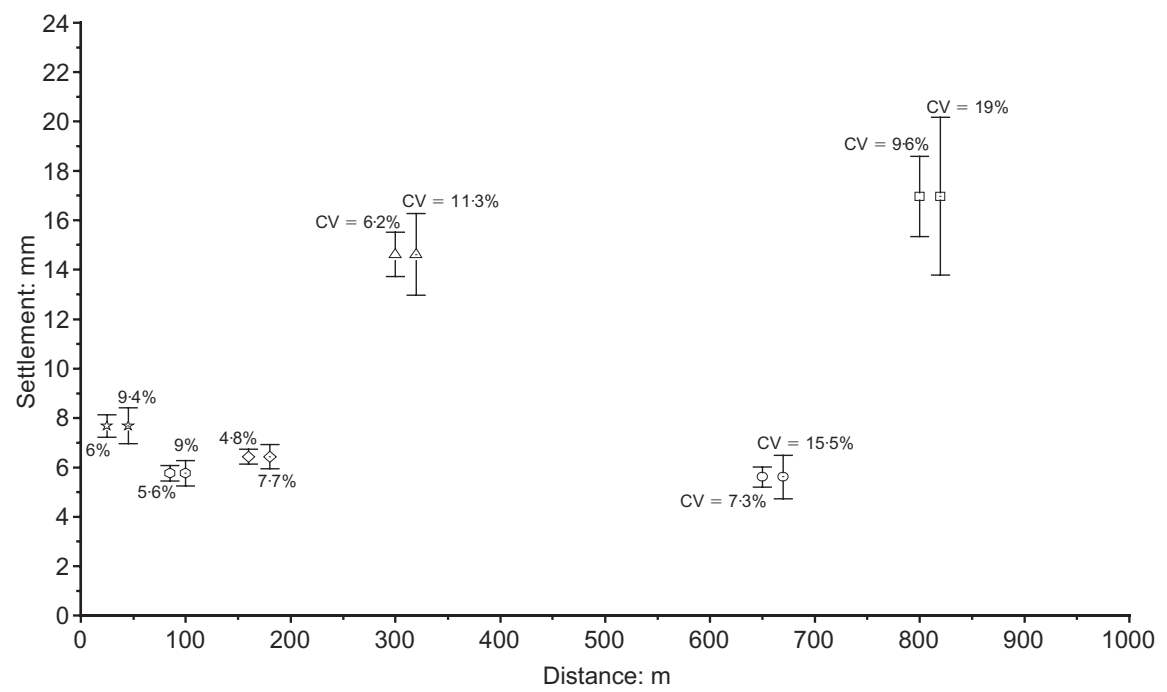

(b)

Fig. 14. Variation of surface settlement at end of stage 1: (a) mean position of tunnel; (b) actual position of tunnel. $d_{\mathrm{r}}$, rheological autocorrelation distance; $d_{\mathrm{s}}$, stratigraphic autocorrelation distance

no correlation between the stiffness of the different layers. Given its effect on the variance, an analysis of the interlayer correlation should be undertaken in order to be able to control this hypothesis.

(c) The mean settlement calculated in the entire area varies between 4.5 and $19.7 \mathrm{~mm}$, which can be represented by considering a pseudo variance of $57 \%$. Thus we can establish that the mean settlement variance determined for the entire studied area is almost 5.5 times higher than the variance associated with any single given zone. In such a study, it is therefore better to calculate the settlement in different sections, using mean values of the stiffness and of the position of the soil layers.

(d) The maximum uncertainty in the surface settlement in any given zone is about $14 \%$ when the autocorrelation distance for the mechanical properties is equal to the stratigraphic autocorrelation distance. It is noted that the coefficient of variance was multiplied by 1.36 in comparison with the previous case, for which the autocorrelation distance was equal to zero. The variance therefore depends on the autocorrelation distance, as was previously assumed. However, its influence on the results remains small in comparison with the evolution of the mean settlement in the studied area. As for the mean settlement variance established for the entire studied area, it is, in the present case, four times bigger than the variance in any given zone. This hypothesis on the horizontal autocorrelation distance did not bring any new element to the study of uncertainties in the settlement predictions. Correlation between the mechanical properties of the various layers probably exists. This possible correlation was not considered in this work, which led to an increase in the variance of the settlement. Therefore the study needs to be prolonged in order to investigate the influence of the correlation between soil layers (vertical analysis) on the settlement predictions.

(e) If the true position of the tunnel is considered, the calculated settlement varies between $5.6 \mathrm{~mm}$ and $17 \mathrm{~mm}$, which represents a range smaller than that obtained for constant mean tunnel position. However, this difference is small. One can state that the 
calculations do not bring into evidence significant variations in the surface settlements due to the position of the tunnel, knowing that, in the present case, the maximum difference between the mean position and the true position of the tunnel is $6 \mathrm{~m}$. These variations are of the same order of magnitude as the uncertainties due to the soil mechanical properties variability in a given section. The evolution of the mean settlement is regular along the entire layout. The mean settlement gradient scarcely changed $(0.078 \mathrm{~mm} / \mathrm{m}$ as against $0.07 \mathrm{~mm} / \mathrm{m}$ previously).

( $f$ ) By considering the true position of the tunnel, the maximum uncertainty in the surface settlement in a given zone is of the order of $9.6 \%$ when the autocorrelation distance is zero. The coefficient of variance, as one would expect, is of the same order of magnitude as in the previous case.

(g) The mean calculated settlement in the entire area varies between 5.6 and $17 \mathrm{~mm}$, which may be represented by a pseudo-variance of $50 \%$. This value integrates, as well as the mechanical properties and stratigraphy variability, the influence of the tunnel position.

\section{CONCLUSIONS}

This study aimed to validate numerical methods used to estimate the influence of the stratigraphy and mechanical properties variability of an urban soil, and to evaluate the effects of underground construction, considered as a statistical variable. The work was based on a case study, the site of the D Line extension of the Lyon subway.

Concerning the effect of stratigraphy variability on the settlement prediction, one can maintain that, for the Lyon site, the coefficient of variance of the mean settlement determined for the entire studied area $(600 \mathrm{~m}$ long) was $\pm 32 \%$ during the partial deconfinement before the installation of the coating (phase 1). This uncertainty reached $\pm 63 \%$ if the two phases of construction (both phase 1 , and phase 2 corresponding to a total deconfinement of the coating) were considered. Statistical analysis of the mean surface settlement led to the determination of a pseudo-structure of these estimates, characterised by a autocorrelation distance that gives useful information on the amount of investigation necessary to analyse an underground structure. For the studied site, the maximum distance between two soil investigations was found to be of the order of $200 \mathrm{~m}$. One should note that this distance integrated an intrinsic characteristic of the soil (its natural variability) and a construction condition (the tunnel position).

In a cross-section, the coefficient of variance of the surface settlement was of the order of $\pm 18 \%$ at the end of stage 1 and $\pm 43 \%$ at the end of phase 2 , taking into account only the stratigraphic variability. Thus it appeared from this analysis that the variability of the surface settlement in a section was smaller than the variability of the mean settlement measured on the whole layout. It could be, in this case, advisable to study the greatest possible number of sections rather than to analyse a single section in a very refined way. This result must be confirmed on other sites.

This uncertainty was determined by using a well-defined procedure in order to estimate the position of each soil layer roof and its variance. The coherence of this procedure was justified by the intermediate results. In order to validate this procedure more widely, we suggest applying it for the stratigraphic characterisation of other urban sites.

Concerning the effect of the variability of the soil mechanical properties on the settlement predictions, the results showed that the coefficient of variance of the surface settlement in a given section was of the order of $19 \%$ at the end of stage 1 . This coefficient of variance reached $\pm 37 \%$ if the variability of both stratigraphy and mechanical properties was considered. The variance of the mean settlement established for the entire studied area $(900 \mathrm{~m})$ was of the order of $57 \%$, taking into account the variability of the stratigraphy and of the mechanical properties. Thus it can be emphasised that the mean settlement variance over the entire studied area is 1.6 times bigger than the variance for a given section. In such a study it is therefore more relevant to calculate the settlement in different sections, using mean values of the mechanical properties and of the position of the soil layers, rather than perform a refined analysis for a specific section.

All the results presented in this study are dependent on the modelling hypotheses. In fact, the assumptions of a constant deconfinement ratio and a constant initial stress state along the whole layout were two major hypotheses that, if not true, could alter some of the conclusions of this work. Therefore this study should be considered mainly as a first approach for the risk associated with an underground excavation by the use of two tools. Some results have been proposed and need to be compared with those achieved by a similar study on other sites or with those achieved on the same site by means of more sophisticated methods and models. It is clear that the deconfinement ratio depends somehow on the configuration of the ground and especially on the number of layers crossed by the tunnel. One has also to assume that a correlation between the mechanical properties of the various layers could exist. This possible correlation was not considered in this work, which led to minimising the variance of the settlement. Therefore the study needs to be prolonged in the future in order to investigate the influence of these different assumptions on the settlement predictions.

\section{ACKNOWLEDGEMENTS}

The work described in this paper is in part supported by the Programme Ville du Ministère de l'Education Nationale. de la Recherche et de la Technologie.

\section{REFERENCES}

Baecher, G. B. \& Ingra, T. S. (1981). Stochastic FEM in settlement predictions. J. Geotech. Engng Div., ASCE, 107, No. 4, 449-463.

Baise, L. G. \& Higgins, R. B. (2003). Geostatistical methods in site characterization. In Applications of statistics and probability in civil engineering (eds A. Der Kiureghian, S. Madanat and J. M. Pestana) pp. 1195-1202. Rotterdam: Millpress.

Barthélémy, S. (1999). Evaluation par une reconnaissance géotechnique optimisée des désordres engendrés sur les ouvrages. Mèm. DEA MSOE, Ecole Central Paris.

Bernat, S. (1996). Modélisation du creusement d'un tunnel en terrain meuble.

Boulefkhad, T. (1986). Influence de la variabilité des propriétés des sols sur le calcul des tassements des fondations superficielles. Thèse de doctorat, Université de Clermont II.

Breysse, D. \& Frappa, M. (1999). Interactions sol- ouvrages: pour une approche améliorée de la variabilité des terrains. Journées nationals Fiabilité des matériaux et des structures, 98, 219-228.

Breysse, D. (2002). Influence of soil variability on differential settlements of buildings. Rev. Fr. de Génie Civ. 6, No. 3. 409-419.

Brooker, P. (1979). Kriging. Engng Min. J. 180, No. 9, 148-153.

Cambou, B. (1975). Application of first order uncertainty analysis in the finite element method in linear elasticity. Proc. 2nd Int. Conf. on Application of Statistics and Probability in Soil and Structure Engineering, Aachen, 67-87.

Cornell, C. A. (1971). First-order uncertainty analysis in soils 
deformation and stability. Proc. 1st Int. Conf. Applications of Statistics and Probability in Soil and Structural Engineering, Hong Kong, 130-144.

DeGroot, D. J. (1996). Analyzing spatial variability of in situ soil properties. Proc. Uncertainty '96, Uncertainty in the Geologic Environment: From Theory to Practice, 1, 210-238. Reston, VA: American Society of Civil Engineers

Deplagne, F. \& Bacconnet C. (1993). Analyse structurale d'une digue en argile. Cah. Gèostat. 3, 181-188.

Ditlevsen, O. (1980). Uncertainty modeling with applications to multidimensional civil engineering systems. New York: McGraw-Hill.

Favre, J. L. \& Genevois, B. (1987a). Effet de la variabilité spatiale des paramètres du sol sur la variance de la capacité portante des fondations superficielles. Proc. ICASP5, Vancouver.

Favre, J. L. \& Genevois. B, (1987b). Analyse de la sécurité des fondations superficielles vis-à-vis d'un défaut de portance: effet de la variabilité spatiale des paramètres du sol. Rev. Fr. Géotechnique, No. 39, 33-40

Favre, M. (1983). Etude géostatistique du noyau du barrage LG3: Complexe de la baie James. Séminaire sur les méthodes probabilistes en géotechnique, Lausanne.

Haldar, A \& Miller, F. J. (1984a). Statistical estimation of cyclic strength of sand. J. Geotech. Engng 110, No. 12, 1785-1802.

Haldar, A. \& Miller, F. J. (1984b). Statistical estimation of relative density. J. Geotech. Engng 110, No. 4, 525-530.

Haldar, A \& Tang, W. H. (1979). Probabilistic evaluation of liquefaction potential. J. Geotech. Engng 105, No. 12, 145-163.

Jaksa, M. B. (1995). The influence of spatial variability on the geotechnical design properties of a stiff, overconsolidated clay. $\mathrm{PhD}$ thesis, University of Adelaide, Australia.

Jaksa, M. B., Kaggwa, W. S. \& Brooker, P. I. (1993). Geostatistical modelling of the spatial variation of the shear strength a stiff, overconsolidated clay. Proceedings of the conference on probabilistic methods in geotechnical engineering, Canberra, pp. 185-194.

Li, K. S \& White, W. (1987). Probabilistic approaches to slop design, Research Report No. 20, Department of Civil Engineering, University College, Australian Defence Force Academy, University of New South Wales.

Liu, B. L., Li, K. S \& Lo, S.-C. R. (1993). Effect of variability on soil behaviour: a particulate approach. Proceedings of the conference on probabilistic methods in geotechnical engineering, Canberra, pp. 201-205.

Magnan, J. P. (1982). Méthodes statistiques et probabilistes en mécanique des sols. Paris: Presses ENCP.

Mellah, R. (1999). Modélisation stochastique par elements finis en élastoplasticité appliquée a la geomécanique. $\mathrm{PhD}$ dissertation, Ecole Nationale Supérieure de Géologie de Nancy.

Ménard, L. (1975). Règles d'utilization des essais pressiomètriques pour le calcul des fondations. Sols Soil Magazine, No. 26.

Mostyn, G. R. \& Soo, S. (1992). The effect of auto-correlation on the probability of failure of slopes. Proc. 6th Australia-New Zealand Conf. on Geomechanics, Christchurch, 542-546.

Nobre, M. M \& Sykes, J. F. (1992). Application of Bayesian kriging to subsurface conditions. Can. Geotech. J., 589-598.

Paraseau, W. G. (1973). Influence of rock property variability on mine opening stability. Proc. 9th Canadian Rock Mechanics Symp.

Phoon, K. K. \& Kulhawy, F. H. (1999a). Characterization of geotechnical variability. Can. Geotech. J., 36, No. 4, 612-624.

Phoon, K. K. \& Kulhawy, F. H. (1999b). Evaluation of geotechnical property variability. Can. Geotech. J., 27, No. 5, 617-630.

Riou, Y., Emeriault, F., Breysse, D. \& Cambou, B. (2000). Evaluation des désordres lors d'un creusement de tunnel en site urbain: quelle fiabilité dans les modélisations numériques. Proc. XIIème Colloque Franco-Polonais. Paris.

Sadki, N. (2001). Faisabilite de modeles de terrain en offshore. $\mathrm{PhD}$ dissertation, Ecole Centrale de Paris.

Soulie, M., Montes, M. \& Sayegh, G. (1990). Modeling spatial variability in soil parameters. Can. Geotech. J. 27, No. 5, 617-630.

Su, Y. L., Wang, Y. J. \& Stefanko, R. (1969). Finite element analysis of underground stresses utilizing stochastically simulated material properties. Proc. 11th US Symp. on Rock Mechanics, Berkeley, CA.

Terzaghi, K. (1955). Influence of geologic factors on the engineering properties of sediments. Econ. Geol., 50, 557-618.

Wickremesinghe, D. \& Campanella, R. G. (1993). Scale of fluctuation as a descriptor of soil variability. Proceedings of the conference on probabilistic methods in geotechnical engineering, Canberra, pp. 233-239. 